Licença CC BY Artigo distribuído sob os termos Creative Commons, permite uso e distribuição irrestrita em qualquer meio desde que o autor credite a fonte original.

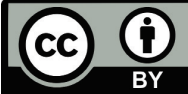

\title{
O USO DE GEOLOCALIZAÇÃO PARA COMPREENDER PRÁTICAS ESPACIAIS DE TURISTAS E RESIDENTES
}

\author{
THE USE OF GEOLOCATION TO UNDERSTAND SPATIAL PRACTICES \\ OF TOURISTS AND RESI-DENTS
EL USO DE LA GEOLOCALIZACIÓN PARA COMPRENDER LAS PRÁCTICAS ESPACIALES DE TURIS-TAS Y RESIDENTES.

\author{
SARAH MARRONI MINASI \\ LUCIANO TORRES TRICÁRICO²
}
'UNIVERSIDADE FEDERAL DO RIO GRANDE, SANTA VITÓRIA DO PALMAR, RIO GRANDE DO SUL, BRASIL
²UNIVERSIDADE DO VALE DO ITAJAÍ, BALNEÁRIO CAMBORIÚ, SANTA CATARINA, BRASIL

\section{DATA DE SUBMISSÃO: 30/04/2021 - DATA DE ACEITE: 03/06/2021}

\begin{abstract}
RESUMO: O processo de urbanização turística materializa no território a infraestrutura necessária para o turis-mo. Com isso, age na formação de centralidades voltadas para atendimento de necessidades de lazer e entrete-nimento, deixando em segundo plano as necessidades de uso do cotidiano. Nesse contexto, surge o questiona-mento sobre como é a relação de turistas e moradores no território apropriado pela urbanização turística. O objetivo estabelecido foi o de compreender a prática espacial de turistas e residentes nos territórios da urbani-zação turística nos destinos turísticos Gramado e Canela, RS e São Joaquim e Urubici, SC. Foram coletados dados usando a interface de programação de aplicativos. Os dados coletados tiveram como base as hashtags para as postagens utilizadas em referências aos destinos turísticos em análise. A base de dados formada agregou os seguintes itens: identificador, geolocalização e data da postagem. Os resultados indicaram que o quantitativo de postagens de turistas é expressivamente superior ao dos moradores. Também, independente da origem das postagens, as geolocalizações se concentram nas áreas centrais e são influenciadas pela presença de elementos icônicos e atrativos turísticos. Deste modo, foi possível perceber que o processo de apropriação de urbanização turística repercute no uso do território urbano, contribuindo para a que o uso do turista prevaleça sobre o uso do morador.
\end{abstract}

PALAVRAS-CHAVE: Urbanização turística; Práticas espaciais; Turistas; Residentes; Geolocalização.

\footnotetext{
Sarah: Professora no Instituto de Ciências Humanas e Informação, Universidade Federal do Rio Grande, Santa Vitória do Palmar, Rio Grande do Sul, Brasil. Doutora em Turismo e Hotelaria, Universidade do Vale do Itajaí, Balneário Camboriú, Brasil. E-mail: sarahminasi@gmail.com Orcid: https://orcid.org/0000-0002-1 193-3274.

Luciano: Coordenador do Programa de Pós-graduação em Turismo e Hotelaria (PPGTH) da Universidade do Vale do Itajaí (UNIVALI), Balneário Camboriú, Santa Catarina, Brasil. Doutor em Arquitetura e Urbanismo pela Faculdade de Arquitetura e Urbanismo (FAU) da Universidade de São Paulo (USP), São Paulo, São Paulo, Brasil. E-mail: tricarico@univali.br Orcid: https://orcid.org/0000-0003-3307-8229.
} 
Abstract: The process of tourism urbanization materializes the necessary infrastructure for tourism within a territory. It acts in the formation of centralities focused on meeting the needs of leisure and entertainment, placing everyday conditions of use in the background. In this context, question arises of the relationship between tourists and residents in the territory that has been appropriated for tourism urbanization. The objective of this work was to understand the spatial practice of tourists and residents in the territories of tourist urbanization of the tourist destinations Gramado and Canela, RS and São Joaquim and Urubici, in the Brazilian state of Santa Catarina. Data were collected using the application programming interface. The data collected was based on hashtags to the posts used in references to the tourist destinations under analysis. The database formed included the following items: identifier, geolocation, and date of posting. The results indicate that the number of posts by tourists is significantly higher than that of residents. Regardless of the origin of the posts, the geolocations are concentrated in central areas influenced by iconic elements and tourist attractions. Thus, it was perceived that the process of appropriation of tourism urbanization has repercussions on the use of the urban territory, contributing to its use by tourists prevailing over its use by local residents.

KEY-WORDS: Tourism Urbanization; Spatial Practices; Tourists; Residents; Geolocation.

RESUMEN: El proceso de urbanización turística materializa la infraestructura necesaria para el turismo en el territorio. Con ello, actúa en la formación de centralidades enfocadas a satisfacer las necesidades de ocio y entretenimiento, dejando en un segundo plano las necesidades del uso cotidiano. En este contexto, surge la pregunta sobre la relación entre turistas y residentes en el territorio apropiado para la urbanización turística. El objetivo establecido fue comprender la práctica espacial de los turistas y residentes en los territorios de urbanización turística en los destinos turísticos Gramado y Canela, RS y São Joaquim y Urubici, SC. Los datos se recopilaron utilizando la interfaz de programación de aplicaciones. Los datos recopilados se basaron en los hashtags de las publicaciones utilizadas en las referencias a los destinos turísticos analizados. La base de datos formada agregó los siguientes elementos: identificador, geolocalización y fecha de publicación. Los resultados indicaron que el número de puestos turísticos es significativamente mayor que el de residentes. Asimismo, independientemente del origen de los postes, las geolocalizaciones se concentran en las áreas centrales y están influenciadas por la presencia de elementos icónicos y atractivos turísticos. Así, se pudo percibir que el proceso de apropiación de la urbanización turística repercute en el uso del territorio urbano, contribuyendo a que el uso de los turistas prevalezca sobre el uso de los residentes..

PALABRAS CLAVE: Urbanización turística; Prácticas espaciales; Turistas; Residentes; Geolocalización.

\section{INTRODUÇÃO}

Como a cidade é significada? Como são significados os modos de viver e de visitar? O uso para o turista e para o morador não é o mesmo? Na cidade se estabelece uma simultaneidade, a reunião dos conteúdos da vida urbana (Lefebvre, 1991), entre eles o cotidiano e o turismo. A cidade é lugar dos conflitos sociais (Corrê, 2007) e desvela as práticas espaciais dos usos do espaço. Ao pensar na apropriação pelo turismo, é possível observar que os espa-ços habitados pelos turistas tendem a ser meros fragmentos da cidade que os rodeia (Judd, 2015).

A urbanização turística é seletiva ao transformar o território em mercadoria, o que implica também na seletividade no fluxo turístico. Nesse sentido, é viável traçar um paralelo com os conceitos de territórios luminosos e opacos de Santos (2008). Os primeiros remetem aos espaços da beleza, de tudo aquilo que o dinheiro pode comprar, dos privilégios, espaços pertencentes à classe dominante, o território turístico. Enquanto os segundos se constituem como verdadeiros espaços esquecidos e fora de qualquer imaginário turístico. 
Se os territórios não se misturam, turistas e moradores também estão propensos a isso. 0 processo de urbanização turística age para que o turismo aconteça de forma concen-trada nas partes do território mais convenientes. A centralidade produzida afasta os outros usos da cidade fazendo com que as práticas espaciais de moradores sejam vividas de forma diferente por conta da atividade turística (Melgaço, 2010; Moreira, 2013).

A geolocalização dos usuários, turistas ou residentes que utilizam redes sociais per-mite analisar um conjunto de dados com suas características e mobilidade em um território. Com o uso dos Sistemas de Informação Geográfica esses dados podem ser transformados em um banco de dados para análises espaço-temporais e fornecer informações relevantes sobre o comportamento das pessoas (turistas ou moradores) para o planejamento urbano e gestão do turismo. A visualização das posições geográficas das fotografias tiradas pelos tu-ristas é um método promissor para medir a atividade turística nos espaços urbanos (Kádar, 2014; Lopes, Remoaldo \& Ribeiro, 2018; Callau, Albert \& Giné, 2019; Zhang, Chen \& Li, 2020). A maioria dos sites de compartilhamento de fotos na internet oferece a possibilidade de "marcação geográfica", resultando em informações geográficas recuperáveis por ban-cos de dados usando a API (Application Programming Interface) (Baumann, 2015) desses sites (Lopes et al., 2018; Callau et al., 2019).

Esses conjuntos de dados podem ser visualizados em mapas digitais, o que torna expressivas as correlações da densidade da foto e dos objetos geográficos de uma determina-da área. É possível diferenciar as fotos tiradas pelos residentes e visitantes examinando in-formações do perfil do usuário específico. Os mapas resultantes revelam conexões interes-santes das atrações turísticas das cidades e as práticas espaciais de turistas e moradores.

Dessa forma, a pesquisa possui o seguinte objetivo geral: compreender a prática espacial de turistas e residentes nos territórios da urbanização turística nos destinos turísticos Gramado e Canela, RS e São Joaquim e Urubici, SC. Como desdobramento, o objetivo específico: discutir validações epistemológicas para categorias de análise do materialismo históri-co dialético em práticas de urbanização turística. Para isso, aborda a coleta e análise de dados sobre a presença física de turistas e moradores a partir de dados publicados aberta-mente em redes sociais e propõe uma discussão em profundidade acerca da epistemologia adotada para a pesquisa, o materialismo histórico dialético.

A pesquisa foi realizada em quatro casos no sul do Brasil, dois no Estado de Santa Catarina e dois no Estado do Rio Grande do Sul. Foram escolhidas as cidades de Canela e Gramado (RS) e São Joaquim e Urubici (SC). Os casos estudados foram escolhidos conside-rando a lacuna de estudos de urbanização turística em cidades que não estão localizadas no litoral, sendo quatro destinos turísticos de serra. Ainda, apresentam semelhanças quanto ao tipo de turismo que desenvolvem, fortemente vinculado ao clima frio e à paisagem natural. Ao mesmo tempo, apresentam aspectos distintos quanto a relevância do turismo como ati-vidade econômica.

Para a coleta de dados da pesquisa, foram usadas as localizações geográficas das fo-tografias postadas desde a primeira postagem com a hashtag. Hashtag é uma palavra ou expressão precedida de um cardinal (\#) para facilitar a pesquisa de um determinado tema. Isso torna a publicação indexada dentro de um tema (Baumann, 2015). Com base nisso, foi possível desenhar geovisualizações para revelar o comportamento de concentração e dis-persão dos turistas e moradores nos casos selecionados. 
Os métodos estabelecidos para registro do comportamento de turistas e moradores nas áreas urbanas apresentam algumas limitações quanto à espacialidade. A análise de postagens geograficamente posicionadas combina a precisão de informações baseadas no Sistema Global de Posicionamento - GPS e o acesso a grandes conjuntos de dados. Como contribuição, os tipos de resultados gerados apresentam correlações e padrões espaciais sobre os destinos turísticos. O que possibilita o aprofundamento de análises sobre os diferentes níveis de atividades de residentes e turistas em locais específicos.

\section{PRÁTICA ESPACIAL URBANA}

O território e seus usos são expressões das relações sociais, mas também as influen-ciam. Logo, existe uma realidade material independente e como aborda Lefebvre (1991) sobre a produção do território, este não pode ser entendido como indissociável da realidade social urbana.

Com isso, as questões da produção do território são da realidade urbana, da cidade e da vida cotidiana. Na perspectiva de Villaça (2017), são as forças sociais que atuam e suas formas de atuação. Portanto, a dimensão do intraurbano cerca agentes, processos e formas espaciais. Todos sob a égide da estrutura econômica (Ferreto, 2020).

A partir das formas de uso e ocupação do território, estão os conflitos sociais urbanos expondo que as formas de apropriação subordinadas ao capital expressam movimentos e momentos de "choque" (Lefebvre, 1991). Em vista disso, é preciso levar a discussão sobre o urbano para a noção de produção desse território. Ainda mais considerando o momento da sociedade em que o território assume parte determinante no modo de produção capitalista. Um modo de produção imbricado por uma dialética em que o território é produto que se consome ao mesmo tempo em que é meio de produção (Ferreto, 2020).

Para Carlos (2011), é preciso pensar o processo de reprodução espacial urbana considerando suas dimensões. Um movimento que revela a transição da produção do espaço à produção do urbano, contemplando as práticas espaciais. É na prática espacial que se desvendam os usos do espaço (Lefebvre, 1991).

A prática espacial contempla a produção e reprodução, as localizações particulares e os conjuntos espaciais de cada formação social (Lefebvre, 1991). Ainda, revela de cada membro o seu relacionamento com aquele território. Não sem considerar que, como produ-to da vida em sociedade, o território é condicionado (e condiciona) às demandas econômi-cas. Aqui, representadas pelas demandas da atividade turística.

Com isso, o território é orientado pela racionalidade econômica baseada na busca pelo desenvolvimento, ainda que muitas vezes disfarçada pelo desejo de acumulação (Abreu \& Costa, 2017). Um desejo que tem no próprio território sua condição de reprodução, sua matériaprima. Essa possibilidade demonstra as inerentes contradições do sistema capitalis-ta.

O urbano, também lugar da reprodução da vida, acaba por revelar mais contradições. A relação de uso dos lugares em que se realiza a vida, se produz o valor de uso, ao mesmo tempo, onde se produz o valor de troca. De acordo com Carlos (2014), esta contra-dição revela a essência da dialética existente no território e sua reprodução. 
É no território transformado em mercadoria e entreposto pela lógica de consumo que o valor de troca e suas relações subordinam as formas e conteúdo do valor de uso. Va-lor de uso resultado da vida cotidiana, em um território que passa a ser fragmentado, ho-mogeneizado para atender a outras necessidades (Meethan, 1997; Luchiari, 2001; Carlos, 2014).

O modo como a apropriação do território acontece demonstra a fragmentação do urbano. Principalmente, porque essa apropriação é diferente de acordo com quem ou o que participa do processo. É consequência da fragmentação a produção e expressão de uma forma de segregação socioespacial. E a segregação não se manifesta apenas nos temas de moradia, trabalho, mas nas formas de circulação das pessoas, serviços e mercadorias. Isto quer dizer que está intimamente ligada aos diferentes atores sociais e o uso que fazem do território.

Para abordar a fragmentação do território urbano, também é preciso falar da centralização e descentralização. Para Lefebvre (2002) a realidade urbana é formada pela centralidade com áreas especializadas e de segregação. Segundo o autor, qualidades herdadas da cidade da era industrial que tendia à uniformidade, homogeneidade, para a continuidade constrangedora, exemplos das dinâmicas de segregação socioespaciais (Lefebvre, 2002; 2008). De acordo com Ferreto (2020), a centralização e a segregação têm altos níveis de determinação sobre a estrutura intraurbana.

Existe, portanto, uma hegemonia dos espaços que indica a aptidão dos elementos urbanos para promover fluxos de mercadorias, serviços ou pessoas. O que remete a Santos (1996) sobre os territórios luminosos, que pelas densidades técnicas e informacionais se tornam mais aptos a atrair atividades econômicas, capital, organização e tudo que resulta destes. Ao passo que nos territórios opacos está a ausência ou escassez de tais característi-cas.

As áreas centrais são, normalmente, as que possuem atributos de centralidade. Co-mo Spolon $(2011$; 2013) aborda, a centralidade não é exclusividade das áreas geografica-mente centrais ou tradicionalmente centrais. Ainda, podem assumir diversas formas de ex-pressão na cidade capitalista, inclusive se deslocar e derivar subcentros. Nesse sentido, Fer-reto (2020) aborda que podem ser centros de negócios, comércios ou equipamentos de con-sumo coletivo, por exemplo, os equipamentos de uso turístico (Moreira, 2013).

A infraestrutura turística coexiste lado a lado com os outros usos do território, como o comércio, residências, empresas, instituições públicas etc. A vida cotidiana é atravessada pelo turismo, pelo uso que o turista faz do território urbano. Este é o uso do outro, que pode resultar no impedimento do uso de determinados espaços da cidade para turistas e morado-res (Judd, 2015). Dessa forma, interferindo nas práticas espaciais dos atores sociais.

O que a urbanização turística promove é a concentração produtiva do turismo, repercutindo na localização da infraestrutura turística no espaço da cidade. As características da configuração territorial da urbanização turística produzem não somente a relação das pessoas com o território, mas entre as pessoas, nesse caso, turista e residente (Rigatti, 2002).

O turismo como atividade econômica acaba priorizando o lazer do outro (Judd, 2015). O turista é considerado esse outro. Na medida em que se desloca para o destino tu-rístico, o consome, relaciona-se com outros estranhos (em algum nível) e com moradores e depois se 
retira (Mansilla et al., 2019). Um processo que, mesmo temporário, impede o uso de determinados fragmentos da cidade (Abreu \& Costa, 2017).

Embora o espaço público seja concebido para ser público, esse muitas vezes é um conceito meramente teórico. A igualdade entre aqueles que ocupam (conferem valor de uso) e aqueles que transitam (conferem valor de troca), na prática, baseia-se na exclusão.

Afirmar, como Lefevbre (1991), que a cidade é o local do encontro, não é afirmar que esse encontro é isento de conflitos, tampouco é resumido aos conflitos. Os usos do coti-diano ao longo dos anos passaram a conviver com o turismo de forma cada vez mais inten-sa. E o turismo, que começou como um fenômeno eminentemente urbano, apresentava uma convivência equilibrada. Algo que gradualmente se alterou quando o turismo alcançou patamares de fenômeno global (Mansilla et al., 2019)

\section{INTERAÇÃO DE TURISTAS E RESIDENTES NO TERRITÓRIO TURÍSTICO}

Na perspectiva de uma análise do materialismo histórico dialético, a produção do território está imersa na dialética socioespacial, em que a ação dos atores sociais está nos processos de produção e consumo do território urbano (Minasi et al., 2019). Tais ações dos atores, segundo observa Corrêa (2013), tem interesses, estratégicas e práticas espaciais próprias.

No turismo, de modo mais específico, as novas configurações vão gradativamente divergindo do que foi construído pelo processo de formação histórico. A nova forma de uso e ocupação do solo se expande, fazendo surgir novas formas urbanas e novos usos das formas urbanas (Silveira \& Rodrigues, 2015). Com isso, disputam, com a população residente, os espaços.

Mesmo com uma infraestrutura que Ihe é própria, a atividade turística não se concretiza como uma entidade espacial distinta (Ashworth \& Page, 2011). Por isso, o conceito de cidade turística ainda carece de amadurecimento. O território urbano é um conjunto de usos e experiências concentradas em centros ou distritos, podendo também estar dispersas espacialmente (Paiva, 2013). O que diferencia a experiência turística do consumo local são a linguagem, ícones e símbolos próprios do turismo. E a característica definidora, o uso ili-mitado do tempo de lazer (Mullins, 1991).

Para MacCannell (2002), o território urbano apropriado pelo turismo assume a característica de uma natureza híbrida. Portanto, o urbano é o espaço vivido dos moradores e espaço das representações dos e para os turistas (Roscoche, 2014).

Se a relação turismo e cidade é da coexistência de usos, a associação entre turismo e conflito é inerente. Dada a expressão adquirida por essa associação, o debate emergiu com força nos últimos anos (Palomeque, 2015). Os movimentos de crítica ao crescimento e saturação do turismo foram observados em Veneza, Rio de Janeiro, Amsterdã, Barcelona, Palma de Maiorca, alguns dos casos citados por Milano (2018). A partir dessas situações surgiram conceitos como turismofobia e overtourism, que indicam a intolerância ao grande volume de fluxo turístico, logo, uma expressão da hostilidade no turismo ou para com o turismo. 
O overtourism indica o mal-estar com relação ao desenvolvimento turístico resultan-te tanto da saturação quanto do volume de turistas (Milano, 2018). Uma situação que tem como dimensão geográfica o território urbano e acaba por modificar ou substituir o uso cotidiano por um lugar de consumo. Judd (2003) aborda como esse processo levaria ao ex-tremo, transformando a cidade em um parque temático, algo somente para o turismo e o turista.

Cabe destacar que esse seria o extremo oposto, considerando uma escala de apropriação do turismo. Autores como Mullins (1991), Gladstone (1998), Urry (2001) e Bailey (2008) consideram que essa apropriação é parcial, portanto, fragmenta o território urbano em bolhas, centralidades e concentrações para o consumo do turismo.

Lefebvre (1991) em "A produção do espaço" apontava que, onde o turismo ocorre, existe um planejamento maior, mais cuidadoso, centralizado e hierarquizado. As áreas mais utilizadas pelo turismo são priorizadas nos investimentos em infraestrutura básica e turística (Mesquita \& Xavier, 2013). Na medida do possível, controlando não só a experiência de quem consome o território turístico, mas a experiência urbana, buscando eliminar a vida cotidiana (Judd, 2003; Melgaço, 2010).

Nesse contexto, existe priorização e excessivo investimento em infraestrutura turísti-ca a qual não é disponibilizada para a população residente, pois, em muitos casos, já existe uma nítida segregação espacial que inviabiliza a população de usufruir tais benefícios. (Ro-drigues, 1996; Mesquita \& Xavier, 2013; Roscoche, 2014). Para Ashwoth e Page (2011), é a ascensão da privatização do espaço público da cidade, principalmente pelo turismo estar cada vez mais caracterizado como um produto privatizado (Judd, 2015).

Por um lado, o planejamento por meio do processo de urbanização turística é responsável por incorporar, no território, elementos que estão no imaginário do turista. Por outro, a presença do turista e atividades desenvolvidas dão vida ao território turístico (Freytag \& Bauder, 2018). Dessa forma, configuram-se lugares em que há maior presença de turistas do que moradores e mais instalações e serviços para turistas do que para locais (Pearce, 1998).

Rigatti (2002) aponta que, na essência, toda a cidade e sua estrutura física representam o campo de relações de turistas (estranhos) e moradores. Proporcionando, por meio da morfologia urbana, características configuracionais no território urbano para tal. De acordo com Rigatti (2002), o urbano é adaptado para facilitar e dificultar as modalidades de encon-tros entre os atores sociais. As formas têm a função de demarcar a circulação (Melgaço, 2010).

Por consequência, nas cidades que têm a atividade turística como principal atividade econômica, essa relação de adaptação é mais acirrada, visto que as medidas que visam a organização e controle desses encontros não agem sob a totalidade. Residentes precisam manter certo domínio dos espaços cotidianos. Turistas carecem da sensação de segurança e estranhamento controlado para fluidez da experiência turística.

Como apontam Moraes e Tricárico (2006), o processo de urbanização encaminhado pelo turismo penaliza a população local, privando-a de suas práticas espaciais. O solo urbano converte-se em mercadoria, estabelecendo uma relação perversa entre um fictício desenvolvimento e a convergência da população para a cidade. (Gonçalves, 2016). 
Na literatura, é comum encontrar a referência de que o turismo deve produzir um lugar que, primeiro, seja bom para o residente e, depois, para o turista. Consequentemente, se o lugar é bom para o residente, também será para o visitante (Fonseca \& Costa, 2004). Porém, cabe considerar que o turismo é capaz de promover o desenvolvimento, da mesma forma como promover conflito e contradição. Nesse sentido, a centralidade nesta pesquisa está nas relações em que existem nos dois lados, residente e turista (anfitrião e hóspede). Existem dois processos de apropriação e uso de espaços do urbano, constituindo territórios do turismo e territórios da vida cotidiana. Entre esses territórios há interações, relações, complementaridades, conflitos.

Nessa via de mão dupla, surgem distintas modalidades de interações sociais (entre os grupos que compartilham o território) e físicas (dos grupos com o território e do território com os grupos). Algumas pesquisas qualificam a segregação (Roscoche, 2014; Lomelí, 2015; Gonzáles-Pérez et al., 2016), a exclusão (Santos, 2011; Abreu \& Costa, 2017) e a gentrificação (Cocola-Gant, 2018) no contexto da urbanização turística. Interfaces das contradições decorrentes do turismo.

Além das repercussões físicas do turismo no território, cabe analisar como são as práticas espaciais dentro desse contexto. Nas publicações sobre urbanização turística, as práticas espaciais são abordadas como resultado do processo, ou apoiado em uma relação de causa e efeito (Santos, 2011; Mesquisa \& Xavier, 2013; González-Perez et al., 2016; Abreu \& Costa, 2017). Nesse contexto, o caráter inovador está em propor tal perspectiva de análi-se (Roscoche, 2014; Lomelí, 2015; Cocola-Gant, 2018) na busca de contribuir com a lacuna de conhecimento.

\section{DESENHO METODOLÓGICO}

O desenho metodológico é caracterizado por uma abordagem qualitativa-quantitativa, sob a perspectiva do materialismo histórico-dialético. A pesquisa tem como base dados primários coletados a partir de pesquisa documental e analisados segundo seu conteúdo.

A pesquisa documental foi adaptada para técnicas e procedimentos para investigar o comportamento virtual (Gondim et al., 2020). Constituem fontes de dados sites, blogs, redes sociais e outros que tenham a interação de usuários.

O conteúdo gerado pelo usuário (UGC) é a base para o compartilhamento e colaboração de informações na Internet. As tecnologias de informação e comunicação atuais fornecem formas inovadoras de coleta de dados sobre os movimentos turísticos. Os usuários das redes sociais disponibilizam diversas informações ao utilizarem seus perfis online.

O conteúdo gerado pelo utilizador são informações digitais dispostas na forma de texto, som ou imagem. Esse conteúdo é utilizado pela WEB 2.0 a partir do surgimento das redes sociais que possibilitam a comunicação bilateral. O CGU é gerado de forma espontânea (Maurer \& Hinterdorfer, 2013). Existe um volume elevado de publicações que se podem extrair das redes sociais que oferecem informações para variados propósitos (Kádár, 2014). A principal forma de compartilhamento de informações é por meio de fotografias, mas exis-†e um potencial importante na junção da imagem digital aos chamados metadados associados. Metadados são informações associadas como identificadores, tags, comentários, likes, 
geolocalização, entre outros (Donaire, Camprubí \& Galí, 2014). Nesta pesquisa, optou-se por utilizar os metadados como identificadores, data da postagem e geolocalização. Por meio dos identificadores, foi possível fazer a diferenciação das postagens pertencentes a turistas e a moradores (Kádár, 2014).

Para coleta dos dados, foi escolhida de rede social Instagram, pelo grande volume de usuários. A rede social Instagram foi criada como um ambiente para compartilhamento de fotos que podem ou não utilizar indexadores como as hashtags. Após a escolha da rede soci-al para coleta dos dados foi organizada a parte operacional (Figura 1).

Figura 1: Framework metodológico

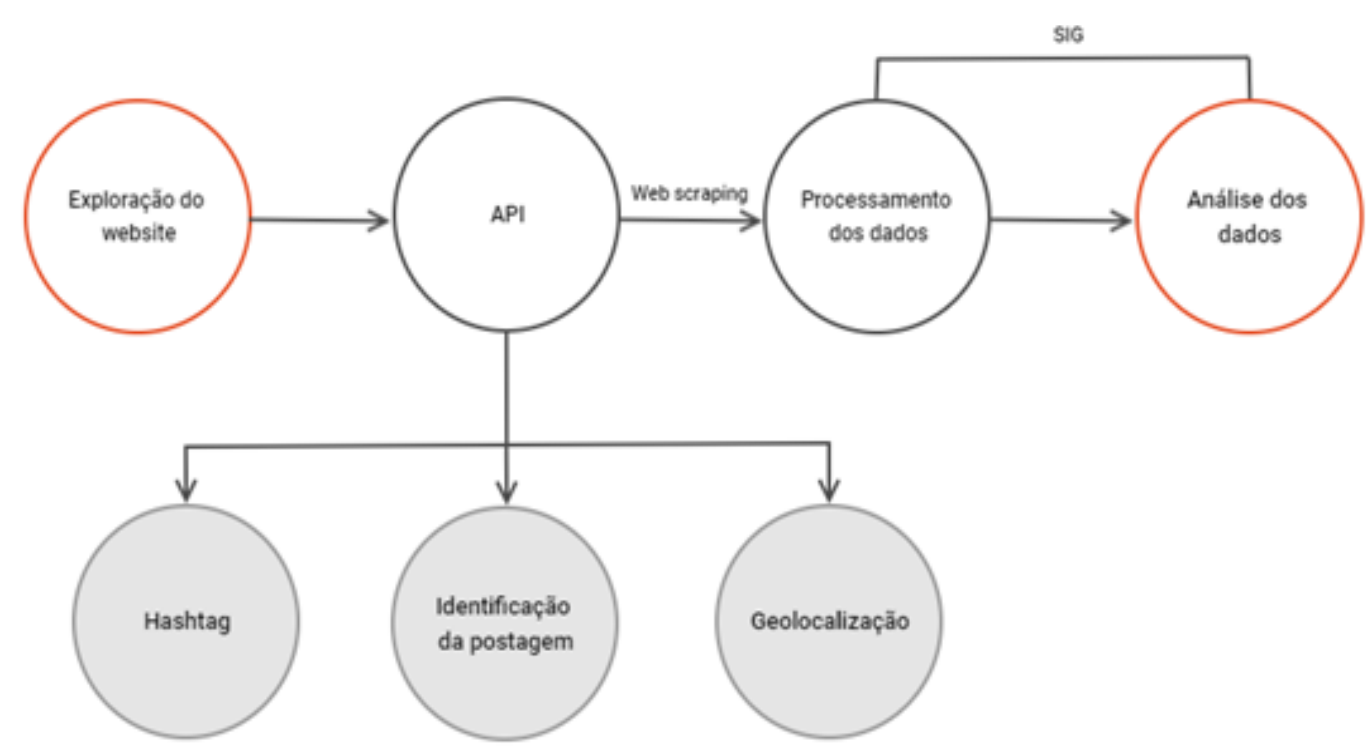

Fonte: elaborado pelos autores (2020)

A delimitação das hashtags para cada um dos casos foi baseada em pesquisa exploratória no Instagram para verificar qual o termo mais utilizado para indexar fotos dos obje-tos de estudo. A partir dessa delimitação, foi realizado o levantamento do número total de postagem analisadas na sua totalidade. Apenas foram excluídas as postagens que apareciam apenas uma vez em determinada localização (Tabela 1).

Tabela 1: Levantamento das postagens (outubro de 2020)

\begin{tabular}{llc}
\hline Destino Turístico & Hashtag & Número de postagens \\
Canela & \#canelars & 107.000 \\
Gramado & \#gramadors & 196.000 \\
São Joaquim & \#saojoaquimsc & 5.600 \\
Urubici & \#urubici & 146.000 \\
\hline
\end{tabular}

Fonte: elaborado pelos autores (2020). 
Os dados coletados foram inicialmente organizados em planilhas e, posteriormente, inseridos no ambiente Quantum GIS - QGIS (versão 3.16.0) para armazenamento, processamento e análise das informações. Assim, foram gerados mapas temáticos para responder ao objetivo de pesquisa.

\section{ÁREA DE ESTUDO}

A área de estudo é composta por quatro municípios reconhecidos como destinos turísticos no sul do Brasil (Figura 2). Os municípios de Canela e Gramado estão localizados no nordeste do Rio Grande do Sul, distante cerca de $115 \mathrm{~km}$ da capital do Estado, Porto Alegre. Integram a Região Turística das Hortênsias, na Serra Gaúcha. Em seus processos de forma-ção histórica passaram por transformações que colocam a região como polo turístico do Rio Grande do Sul (Griebeler et al., 2017). Gramado é um município turístico reconhecido, atrai oportunidades de negócios para investir e qualificar este destino da Região das Hortênsias, de forma a consolidá-lo, cada vez mais, no cenário turístico nacional e internacional (Mecca et al., 2018).

Os municípios de São Joaquim e Urubici estão localizados no planalto sulcatarinense, distante aproximadamente $220 \mathrm{~km}$ da capital do Estado de Santa Catarina, Florianópolis. Os municípios têm passado por transformações decorrentes do desenvolvimento de novas ati-vidades econômicas, dentre as quais se destacam o turismo e, especificamente em São Joa-quim, a vitivinicultura, com a recente produção de vinhos de altitude (Cordeiro, 2006; Losso, 2010).

Figura 2: Mapa de localização da área de estudo

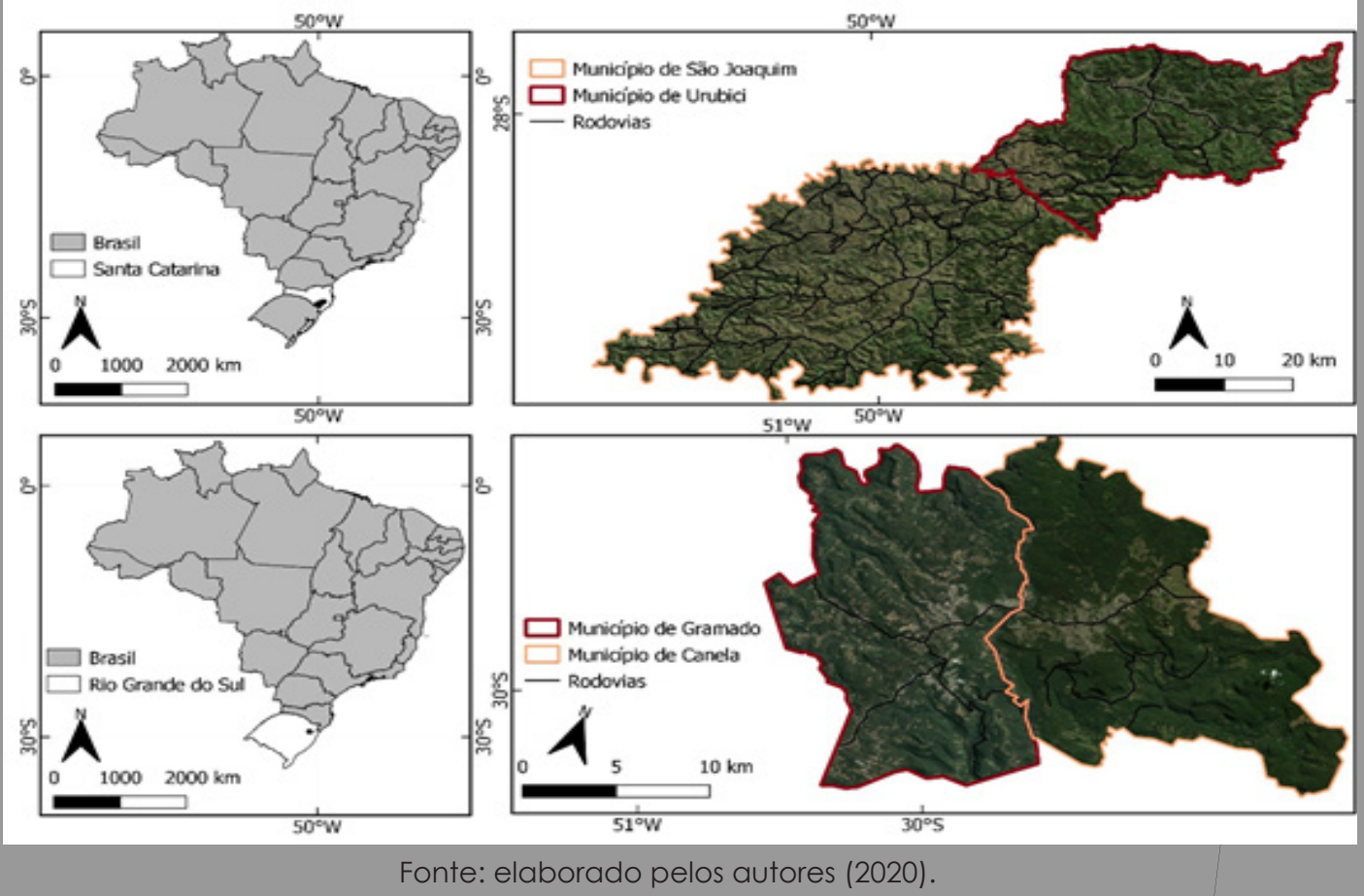

O desenvolvimento da atividade turística nos destinos que compõem a área de estudo se destaca nos seguintes eixos: o turismo de frio, em função do clima de altitude (serra) com expectativa de precipitação de neve e baixas temperaturas; o turismo rural, o enotu-rismo; turismo de eventos; e o turismo cultural. 


\section{RESULTADOS E DISCUSSÃO}

\section{Resultados}

Os dados coletados resultaram em um grande conjunto de localizações. Para otimi-zar a identificação dos pontos algumas medidas foram tomadas e, com isso, uma filtragem dos dados. As fotografias com mesma geolocalização foram agrupadas em um mesmo pon-to. Ainda, foram aplicados mais dois filtros: a exclusão das localizações que apresentavam apenas uma postagem, uma vez que poderia inferir sobre um erro e sobrecarregar a visua-lização; da mesma forma, foram excluídas as postagens com conteúdo publicitário. Ao total foram analisadas 99.813 postagens localizadas em Canela; 179.567 postagens localizadas em Gramado; 3.654 postagens localizadas em São Joaquim; 137.549 postagens localizadas em Urubici. É importante destacar que os resultados não foram gerados com base de informa-ções temporais. A geolocalização não é garantia de que a postagem foi realizada durante a estada na determinada localização. Portanto, não é uma informação com acurácia validada.

O modo mais claro e objetivo de visualizar a distribuição das postagens é adicionan-do um ponto no mapa para cada imagem geolocalizada e disponibilizada online. A Figura 3 resume a distribuição das imagens compartilhadas, diferindo conforme foram tiradas por residentes ou turistas. Na área de estudo, as regiões mais urbanizadas são facilmente reco-nhecidas à primeira vista. Há uma concentração de fotos nas áreas centrais do território urbano. Também fica visível a distribuição ao longo dos eixos principais da rede viária.

Figura 3: Densidade das fotos por caso de acordo com turistas e moradores e relação com a presença de elementos icônicos

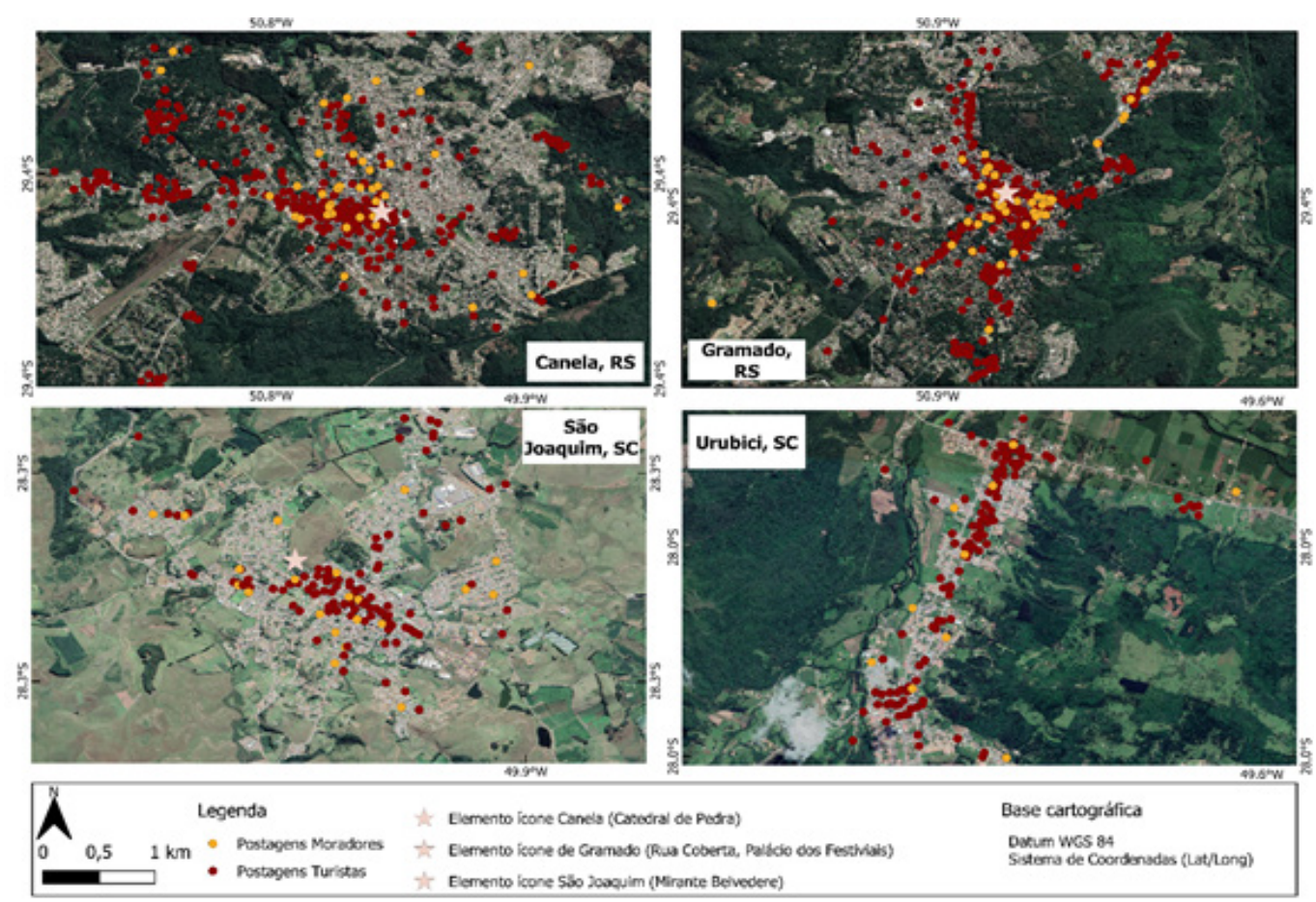

Fonte: elaborado pelos autores (2020). 
A geovisualização das fotografias de turistas demonstra a intensidade da utilização da opção de indexação de postagens por hashtag e atribuição de localização. É possível identificar que o comportamento do turista está concentrado, enquanto as localizações informadas por moradores estão mais dispersas.

Na Figura 4 também está representada a distribuição das fotografias conforme fo-ram tiradas por turistas e residentes em relação à presença dos elementos icônicos de cada destino turístico. A exceção é o caso de Urubici, em que o elemento icônico não é represen-tado por um ponto construído, mas sim pelo relevo natural que circunda a área urbana. Por-tanto, esse elemento icônico não foi representado no mapa.

Os pontos sinalizados permitem a análise da presença turística em torno dos elementos icônicos dentro da cidade. As diferenças associadas a cada caso evidenciam a complexidade nesta relação. Os casos de Canela e Gramado convergem, indicando que o elemento icônico exerce atratividade no fluxo turístico. Enquanto o caso de São Joaquim demonstra que o Mirante Belvedere tem pouco apelo turístico. Essas considerações permitem o estudo e a comparação de qualidades como popularidade, uso turístico-local e complexidade de diferentes locais turísticos.

Figura 4: Relação da localização de atrativos turísticos com a geolocalização das postagens

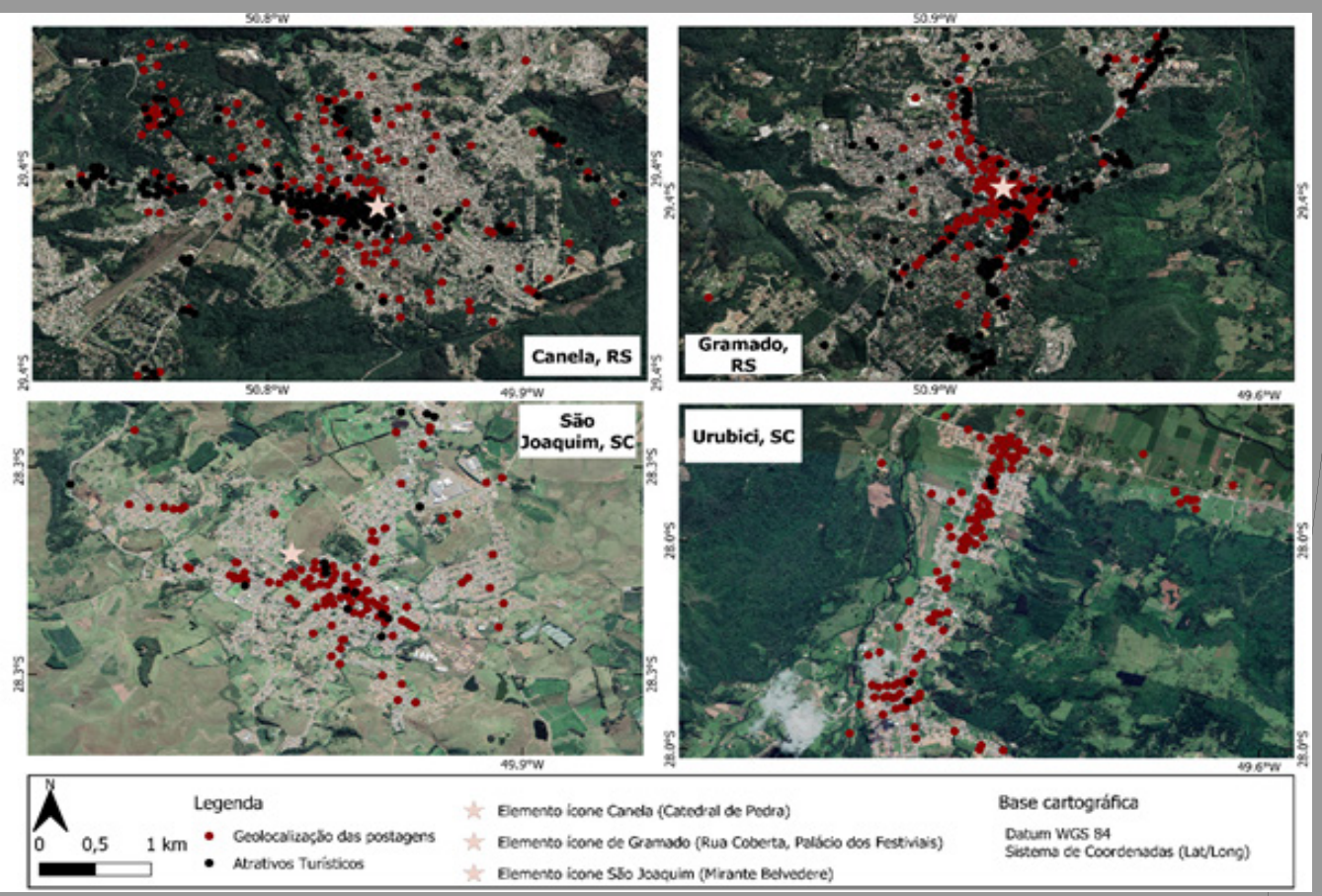

Fonte: elaborado pelos autores (2020).

Na figura 4 estão relacionadas as informações sobre a localização de atrativos turís-ticos e o quantitativo total de postagens geolocalizadas em cada um dos casos. A distribui-ção das postagens apresenta uma correlação com a localização dos atrativos turísticos nos casos de Gramado e Canela. Uma vez que são destinos turísticos com maior concentração de atrativos nos centros urbanos. 
Nos casos de São Joaquim e Urubici, em que os principais atrativos turísticos estão dispersos na zona rural, a concentração de fotografias é associada a presença de outros serviços turísticos. Portanto, uma situação inversa na qual a zona carece de meios de hospedagem e serviços de alimentação, enquanto a zona urbana não dispõe de um número expressivo de atrativos.

\section{DISCUSSÃO DOS RESULTADOS}

As geovisualizações da fotografia turística traçam visivelmente os principais atrativos e percursos visitados pelos turistas, o que permite inferir intensidades de uso turístico que nenhum outro método conseguiu demonstrar até então. Esses padrões visíveis se correlaci-onam com a infraestrutura turística e morfologia das partes centrais dos destinos turísticos em análise.

Algumas das principais semelhanças entre os quatro destinos podem ser deduzidas à primeira vista. Todos os quatro têm um núcleo estendido com uso intensivo de turistas, mas também têm alguns locais principais fora do centro, ainda que o quantitativo seja variável em cada um dos casos. É importante também destacar que, mesmo os destinos turísticos que desenvolvem os segmentos de turismo relacionados ao espaço rural, São Joaquim e Urubici, ainda é no centro urbano que está a maior concentração de turistas.

Os padrões mais característicos nos núcleos urbanos centrais são os axiais, relacio-nados a algumas avenidas ou ruas principais. Na verdade, esses lugares urbanos são atra-ções em si, e os turistas usam rotas representativas em vez de ruas menos atraentes para se deslocar entre outras atrações centrais e maximizar a experiência prevista em um determi-nado momento. Esse comportamento é altamente influenciado pela presença dos elementos ícones, principalmente nos casos de Canela e Gramado.

No nível urbano, as visualizações em escala do mapa das atividades turísticas, deduzidas das imagens geolocalizadas enviadas ao Instagram, tornaram evidentes os fluxos turís-ticos correlacionados às estruturas morfológicas e turísticas dessas quatro cidades.

O mapa de distribuição da infraestrutura turística influencia na determinação da mobilidade dos turistas, por consequência, influencia na mobilidade de moradores; afirmações evidenciadas pelos resultados dos dados coletados. Assim, não se trata de um processo de dispersão espacial do turismo, fica cada vez mais evidente que os centros mantêm o protagonismo na apropriação do turismo. Conforme afirma Moreira (2013), a apropriação pelo turismo implica no adensamento dos serviços ligados à atividade, concentrados nas avenidas mais valorizadas da cidade.

O território urbano é muito mais amplo do que a sua área central, mais intensamen-te visitada e acessada por turistas e pouco vivenciada por moradores. É possível relacionar que a presença de residentes na centralidade apropriada pela urbanização turística é envol-ta em uma relação de prestação de serviço (Moreira, 2013). O uso para lazer e entreteni-mento é prioridade, se não exclusividade, dos estranhos, os turistas. A adaptação do territó-rio para consumo do turismo o torna receptivo para alguns e segregador para outros. Um processo que, além da dimensão estética, também carrega uma carga simbólica (Melgaço, 2010). 
A distribuição das postagens permite constatar a configuração de um território turís-tico nos casos estudados, de maior (Gramado e Canela) ou menor grau (São Joaquim e Uru-bici). A existência de uma zona altamente especializada para consumo turístico é confirma-da pela concentração de turistas e relativa ausência de residentes. Como consequência, sur-gem áreas supervalorizadas pelo turismo, ao mesmo tempo em que as práticas espaciais de moradores são deslocadas. Com isso, a população residente não usufrui dos investimentos postos naquela área (Abreu \& Costa, 2017).

Nesse contexto, o urbano como espaço da vida cotidiana é substituído pela prática da atividade turística. Um processo que tem marcas no território para além das formas urbanas, são marcas também no seu uso e apropriação (Moraes \& Tricárico, 2006; Melgaço, 2010). A urbanização turística ultrapassa a mera dimensão material, resultante da introdu-ção de infraestrutura turística. As repercussões dessa urbanização são sentidas também na formação de centralidades que reproduzem a desigualdade de acesso (Mesquita \& Xavier, 2013), da mesma forma, no consumo de fragmentos do território, como destaca Moreira (2013).

A urbanização turística é marcada pela contradição, uma vez que a atividade turística é fluxo e atração de pessoas, ao mesmo tempo em que é impedimento e afastamento. A urbanização se torna excludente quando é condicionada a um ou poucos usos. A produção e consumo do território atende à valorização e expansão do capital de modo perverso por meio da intensificação da segregação. Por isso, a categoria segregação e gentrificação de análise da urbanização turística na perspectiva do materialismo histórico-dialético (Minasi et al., 2019) é confirmada.

\section{CONSIDERAÇÕES FINAIS}

Os resultados alcançados e a discussão gerada pela pesquisa trazem a compreensão da prática espacial de turistas e residentes nos territórios da urbanização turística nos destinos turísticos Gramado e Canela, RS e São Joaquim e Urubici, SC. É importante considerar que o turismo não é o único que gera conflitos na cidade. Contudo, é um processo que deve ter atenção, devido aos exemplos de outros destinos turís-ticos que buscam uma distribuição espacial mais dispersa do turismo, no intuito de evitar o excesso de concentração como os destinos turísticos que apresentam casos de overtourism. Nesse contexto, os efeitos da fragmentação e centralidade do território apropriado pelo turismo podem não ser desejáveis pelos residentes e ao mesmo tempo insatisfatórios para turistas.

Nos residentes, a configuração do território turístico repercute como o afastamento, a desigualdade de acesso, mesmo que não haja uma barreira física para isso. Segrega porque não atende às necessidades do cotidiano. Nos turistas, repercute mostrando apenas parte da cidade, um território especializado que pode ser confundido com uma espécie de parque temático totalmente distante da realidade. Atrai porque satisfaz o imaginário do que é a experiência turística. Dois usos da cidade que não se aproximam, não de maneira espon-tânea.

As repercussões da urbanização turística provocam a necessidade de buscar novas formas de pensar e organizar os destinos turísticos urbanos, evitando que os usos da cidade sejam excludentes. O acesso e uso do território turístico, mesmo que por diferentes atores, deve ser concomitante. 
Como contribuição o artigo fomenta a discussão sobre as práticas espaciais no nível territorial induzidas pela urbanização turística. Ainda, apresenta a validação da categoria segregação e gentrificação para análise do processo de urbanização turística. Mostra a epistemologia do materialismo histórico-dialético como percurso de pesquisa, que permite analisar o consumo do território apropriado pela urbanização turística. Em termos metodológi-cos, a pesquisa apresenta uma abordagem de coleta e análise de dados que, embora esteja em ascensão nos estudos do turismo, ainda não foi explorada nos estudos de urbanização turística.

A partir dos resultados da pesquisa, surgem insights sobre a densidade de turistas, os pontos de interesse que visitam, bem como o uso dos espaços da cidade pelos moradores. Os dados com geolocalização não se restringem a ser apenas mais uma camada no planejamento, mas, além disso, reconhecem que o território e seu uso são relevantes para compreender o turismo. Esse tipo de informação é útil para melhor orientar o desenvolvimento do turismo estabelecendo um vínculo entre o planejamento do uso e ocupação do território turístico e a cidade.

As limitações da pesquisa encontram-se basicamente na distinção das postagens de turistas e residentes. Ainda que apoiada na literatura existente, é recomendável que estudos desse tipo sejam complementados por outras formas de coleta de dados na intenção de agregar uma triangulação de dados. Por fim, como recomendações para pesquisas futuras é indicado o uso de métodos de entrevista para complementar a análise, bem como buscar a análise de outros metadados, como comentários e curtidas dos conteúdos gerados pelo usu-ário.

\section{AGRADECIMENTOS}

O presente trabalho foi realizado com apoio da Coordenação de Aperfeiçoamento de Pessoal de Nível Superior - Brasil (CAPES) - Código de Financiamento 001.

\section{REFERÊNCIAS BIBLIOGRÁFICAS}

Abreu, L. M., \& Costa, A. N. C. (2017). Turismo e litoral: Transformações espaciais, fragmen-tação urbana e exclusão social no Nordeste do Brasil. Revista Thésis, 2(3), 334-356.

Ashworth, G., \& Page, S. J. (2011). Urban tourism research: Recent progress and current pa-radoxes. Tourism management, 32(1), 1-15.

Bailey, N. (2008). The challenge and response to global tourism in the post-modern era: the commodification, reconfiguration and mutual transformation of Habana Vieja, Cu-ba. Urban Studies, 45(5-6), 1079-1096.

Baumann, F. (2015). Análise da imagem projectada e percebida do destino Lisboa através da fotografia digital. A rede Instagram como nova resposta para a recolha de dados. Dis-sertação de Mestrado, Instituto Politécnico de Leira, Lisboa, Portugal.

Callau, A. À., Albert, M. Y. P., Rota, J. J., \& Giné, D. S. (2019). Landscape characterization using photographs from crowdsourced platforms: content analysis of social media photographs. Open Geosciences, 11 (1), 558-571. 
Carlos, A. F. (2014). Da "organização" à "produção" do espaço no movimento do pensamen-to geográfico. In A.F. Carlos, M. L. Souza \& M. E.B. Sposito (Orgs.). A produção do es-paço urbano: agentes e processos, escalas e desafios. São Paulo: Contexto.

Carlos, A. F. (2011). A condição espacial. Contexto.

Cocola-Gant, A. (2018). Tourism gentrification. In Handbook of gentrification studies. Edward Elgar Publishing.

Cordeiro, W. C. (2006). A vitivinicultura em São Joaquim - SC: uma nova atividade no muni-cípio. Dissertação de Mestrado, Universidade Federal de Santa Catarina, Florianópolis, Florianópolis, SC, Brasil.

Corrêa, R. L. (2007). Diferenciação sócio-espacial, escala e práticas espaciais. Revista Cida-des, 4(6).

Corrêa, R.L. (2013). Segregação residencial: classes sociais e espaço urbano. In P. A. Vascon-celos, R. L. Corrêa \& S. M. Pintaudi (Orgs.) A cidade contemporânea: segregação es-pacial (pp. 38-59). São Paulo: Contexto.

Corrêa, R. L. (2013). Segregação residencial: classes sociais e espaço urbano. A cidade contemporânea: segregação espacial. Contexto.

Donaire, J. A., Camprubí, R., \& Galí, N. (2014). Tourist clusters from Flickr travel photogra-phy. Tourism management perspectives, 11, 26-33.

Ferretto, D. (2020). Categorias de análise intraurbanas na perspectiva teórica da produção do espaço. Terra Livre, 1(54), 170-197.

Fonseca, M. A. P., \& da Costa, A. A. (2004). A racionalidade da urbanização turística em áreas deprimidas: o espaço produzido para o visitante (rationality of touristic urbanisa-tion in depressed zones: the specific space for visitors). Mercator, 3(6).

Freytag, T., \& Bauder, M. (2018). Bottom-up touristification and urban transformations in Paris. Tourism Geographies, 20(3), 443-460.

Gladstone, D. L. (1998). Tourism urbanization in the United States. Urban Affairs Revi-ew, 34(1), 3-27.

Gonçalves, T. M. (2016). A contribuição do pensamento dialético de Henri Lefebvre para a pesquisa interdisciplinar sobre a questão urbana. Tecnologia e Ambiente, 22.

Gondim, C. B., Bolzán, R. E., Espínola, R. S., \& de Oliveira Alexandre, M. L. (2020). Netnogra-fia como Método de Pesquisa em Turismo. Revista Turismo em Análise, 31 (1), 19-36.

González-Pérez, J. M., Remond-Roa, R., Rullan-Salamanca, O., \& Vives-Miró, S. (2016). Ur-ban growth and dual tourist city in the Caribbean. Urbanization in the hinterlands of the tourist destinations of Varadero (Cuba) and Bávaro-Punta Cana (Dominican Repu-blic). Habitat International, 58, 59-74.

Griebeler, M. P. D., Berti, F., \& Junior, A. A. M. (2017). Hierarquização das cadeias produti-vas: diagnóstico das atividades econômicas de Gramado (RS). Ágora, 19(2), 112-124.

Judd, D. (2015). Building the tourist city. Routledge.

Judd, D. (2003). The infrastructure of play: building the tourist city. ME Sharpe.

Kádár, B. (2014). Measuring tourist activities in cities using geotagged photography. Tourism Geographies, 16(1), 88-104. 


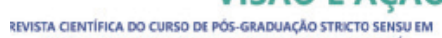
TURISMO E HOTELARIA DA UNIVERSIDADE DO VALE DO ITAJAI

Lefebvre, H. (2002). A Revolução urbana. Editora UFMG.

Lefebvre, H. (2008). Espaço e Política. Editora UFMG.

Lefebvre, H. (1991). The producion of space. Blackwel.

Lomelí, R.C. (2015). Urbanización turístico-costera desigual en Playa del Carmen, Quintana Roo (México). GeoGraphos, 6(77), 107-134. DOI: 10-14198GEOGRA2015.6.7.

Losso, F.B. (2010). A produção de vinhos finos de altitude na região vitivinícola de São Joaquim (SC): uma alternativa para o turismo? Dissertação de Mestrado, Universidade do Vale do Itajaí, Balneário Camboriú, SC, Brasil.

Luchiari, M. T. (2001). Urbanização turística: um novo nexo entre o lugar e o mundo. In C. Serrano, H. Bruhns \& M. T. Luchiari (Orgs.). Olhares contemporâneos sobre o turismo (pp. 105-130). Papirus.

Maccannell, D. (2002). Empty meeting grounds: The tourist papers. Routledge.

Mansilla, J. A., Marcús, J., Boy, M., Yanes, S. \& Aricó, Y. G. (2019). Del planeamiento urba-nístico a la actividad turística. In J. Marcús, J. Mansilla, M. Boy, S. Yanes \& G. Aricó (Orgs.). La ciudad mercancía: turistificación, renovación urbana y políticas de control del espacio público. Buenos Aires: EPUB.

Maurer, C. \& Hinterdorfer, B. (2013). The adoption of Pinterest for destination marketing: the case of austrian destinations. Springer International Publishing.

Mecca, M. S., Bregolin, M., de Paula, A. T., Vieira, L. T., \& Neto, R. D. (2018). O Destino Gramado-RS e a Crise Econômica Brasileira: Uma Análise Baseada no Modelo de Ciclo de Vida do Turismo de Butler/ The Destination Gramado-RS in the Context of the Brazi-lian Economic Crisis: An Analysis Based on Butler's Tourism Lifecycle Model. ROSA DOS VENTOS-Turismo e Hospitalidade, 10(4).

Meethan, K. (1997). York: managing the tourist city. Cities, 14(6).

Melgaço, L. (2010). A cidade e a negação do outro. ComCiência, (118).

Mesquita, D., \& Xavier, G. (2013). O turismo e a sua atuação na expansão do espaço urbano: o caso porto de galinhas-Ipojuca-PE. Turismo-Visão e Ação, 15(2), 207-225.

Milano, C. (2018). Overtourism, malestar social y turismofobia. Un debate controverti-do. PASOS Revista de Turismo y Patrimonio Cultural, 16(3), 551-564.

Minasi, S. M., Ruiz, T. D., Dos Anjos, F. A., \& Tricárico, L. T. (2019). El materialismo histórico dialéctico como base epistemológica para la investigación de la ciudad y la urbani-zación turística. Estudios y perspectivas en turismo, 28(2), 372-392.

Moraes, S. T., \& Tricárico, L. T. (2006). História, cultura e projeto urbano: a barra do rio Camboriú. Revista Paranaense de Desenvolvimento, (1 11 ), 105-127.

Moreira, G.L. (2013). A Reprodução do espaço urbano da cidade de llhéus: turismo, segregação e mercantilização do espaço. Revista da Casa da Geografia de Sobral, 15(1), 32 - 48.

Mullins, P. (1991). Tourism urbanization. International journal of urban and regional rese-arch, 15(3), 326342.

Paiva, R. A. (2013). Sobre a relação turismo e urbanização. Pós. Revista do Programa de Pós-Graduação em Arquitetura e Urbanismo da FAUUSP, 20(33), 126-145. 
Palomeque, F. L. (2015). Barcelona, de ciudad con turismo a ciudad turística. Notas sobre un proceso complejo e inacabado. Documents d'anàlisi geogràfica, 61 (3), 483-506.

Pearce, D. G. (1998). Tourist districts in Paris: structure and functions. Tourism management, 19(1), 49-65.

Rigatti, D. (2002). O turista, o morador e o uso do espaço urbano: interações espaciais em Gramado e Canela. Paisagem e Ambiente, (16), 69-107.

Rodrigues, A. B. (1999). Turismo e espaço: rumo a um conhecimento transdisciplinar. Hucitec.

Roscoche, L. F. (2014). Turismo urbano e a segregação socioespacial: revisitando problemáticas. Revista OKARA: Geografia em Debate, 8(1), 3-20.

Santos, M. (2008). Espaço e método. Ed. USP.

Santos, M. (1996). A natureza do espaço: espaço e tempo: razão e emoção. HUCITEC.

Santos, T. M. S. (2011). Urbanização turística e a produção do espaço nos centros do lazer: um estudo sobre Praia do Forte-Bahia. Revista Geográfica de América Central, 2, 1-15.

Lopes, H. T., Remoaldo, P. C. A. C., \& Ribeiro, V. (2018). The use of photos of the social networks in shaping a new tourist destination: Analysis of clusters in a GIS environ-ment. In J. Rocha \& J. A. Tenório (Eds.). Spatial analysis, modelling and planning. Inte-chOpen.

Silveira, M. A., \& Rodrigues, A. B. (2015). Urbanização turística no Brasil: um foco em Flori-anópolis-Santa Catarina. Via. Tourism Review, (7).

Spolon, A. P. G. (2011). Hotelaria, cidade e capital: o edifício hoteleiro e a reestruturação dos espaços urbanos contemporâneos. Tese de Doutorado, Faculdade de Arquitetura e Urbanismo da Universidade de São Paulo, São Paulo, SP, Brasil.

Spolon, A. P. G. (2013). Movimentos contemporâneos de reestruturação urbana e a ressigni-ficação do ambiente construído de cidades inseridas no circuito mundial de viagens: um olhar sobre os edifícios hoteleiros. Biblio 3w: revista bibliográfica de geografía y ciencias sociales, 18.

Urry, J. (2001). O olhar do turista. Studio Nobel.

Villaça, F. (2017). Espaço intra-urbano no Brasil. Studio Nobel.

Zhang, K., Chen, D., \& Li, C. (2020). How are tourists different?-Reading geo-tagged photos through a deep learning model. Journal of Quality Assurance in Hospitality \& Tou-rism, 21 (2), 234-243.

Contribuição de cada autor na construção do artigo

Sarah Marroni Minasi: Planejamento do estudo, elaboração da metodologia, coleta e análi-se dos dados e redação do artigo.

Luciano Torres Tricárico: Orientação no planejamento do estudo, supervisão das análises dos dados, revisão e edição do artigo. 